\title{
El Mulhacén: la esfinge de Sierra Nevada
}

Manuel Titos Martínez, Dpto. de Historia Contemporánea, Universidad de Granada

\author{
Ahí estuvo y ahí está \\ el Mulhacén, para que \\ pueda ser ascendido \\ y disfrutado, nunca \\ dominado ni vencido
}

Si en el agua está el origen de la vida, la vida en la Península Ibérica comienza en el punto más próximo al cielo, allí donde el agua empieza a discurrir, en la cima más alta de la Penibética: el gran león dormido que desde la Alpujarra se asoma vigilante al resto de Iberia, el cerro del Mulhacén.

Así es como lo contempló Salvador Rueda, que en 1913 escribió los mejores versos sobre Sierra Nevada:

"Una esfinge de insólita largura

de hundidos flancos y alta la cabeza,

finge con su inmutable fortaleza

y su dorso en inmensa curvatura".

Esa inmensa curvatura es en realidad la Alpujarra, tierra inhóspita y levantisca, de destierro y rebelión, de martirio y de venganza, aislada del mundo durante siglos, a la que incluso su fiero protector le dio la espalda y prefirió buscar en el norte la silueta del palacio perdido y nunca olvidado donde nació y del que fue expulsado, no por los reyes de CastiIla, sino por su propio hijo Muhammad, el Rey Chico, el Zogoibi, Boabdil "el desventurado".

Abu-I-Hassan Ali, el Muley Hacen de los textos cristianos fue el antepenúltimo rey de la
Granada nazarí, el padre de Boabdil, quien le destronó y a quien destronó, el esposo de Aixa la Horra, el amante de Isabel de Solís, la cristiana renegada islamizada como Zoraya.

Muley Hacen fue el último de los reyes del Islam granadino que realizó la guerra en serio contra los cristianos; cuentan las crónicas que cuando los Reyes Católicos enviaron a su embajador Juan de Vera para exigir el pago de los tributos atrasados, Muley Hacen respondió cargado de dignidad: "Volveos y decid a vuestros soberanos que ya son muertos los reyes de Granada que pagaban tributo a los cristianos y que en Granada no se labra ya oro, sino alfanjes y hierros de lanza contra nuestros enemigos".

Muley Hacen perdió dos veces el trono: una a manos de su hijo Muhammad XII, Boabdil, y otra en las de su hermano Muhammad XIII, El Zagal. Desengañado de la vida tras ver morir en Almería a su segundo hijo por manos de su propio hermano y forzado por un destino irremediable, Muley Hacen renunció a la lucha y se retiró a Almuñécar, donde murió el 28 de octubre de 1485.

"Llévame a lo más alto de Xolair -fue la última voluntad que manifestó a la fiel Soraya- donde 
(-) Parque Nacional de Sierra Nevada / Foto: Fernando CASTELlón

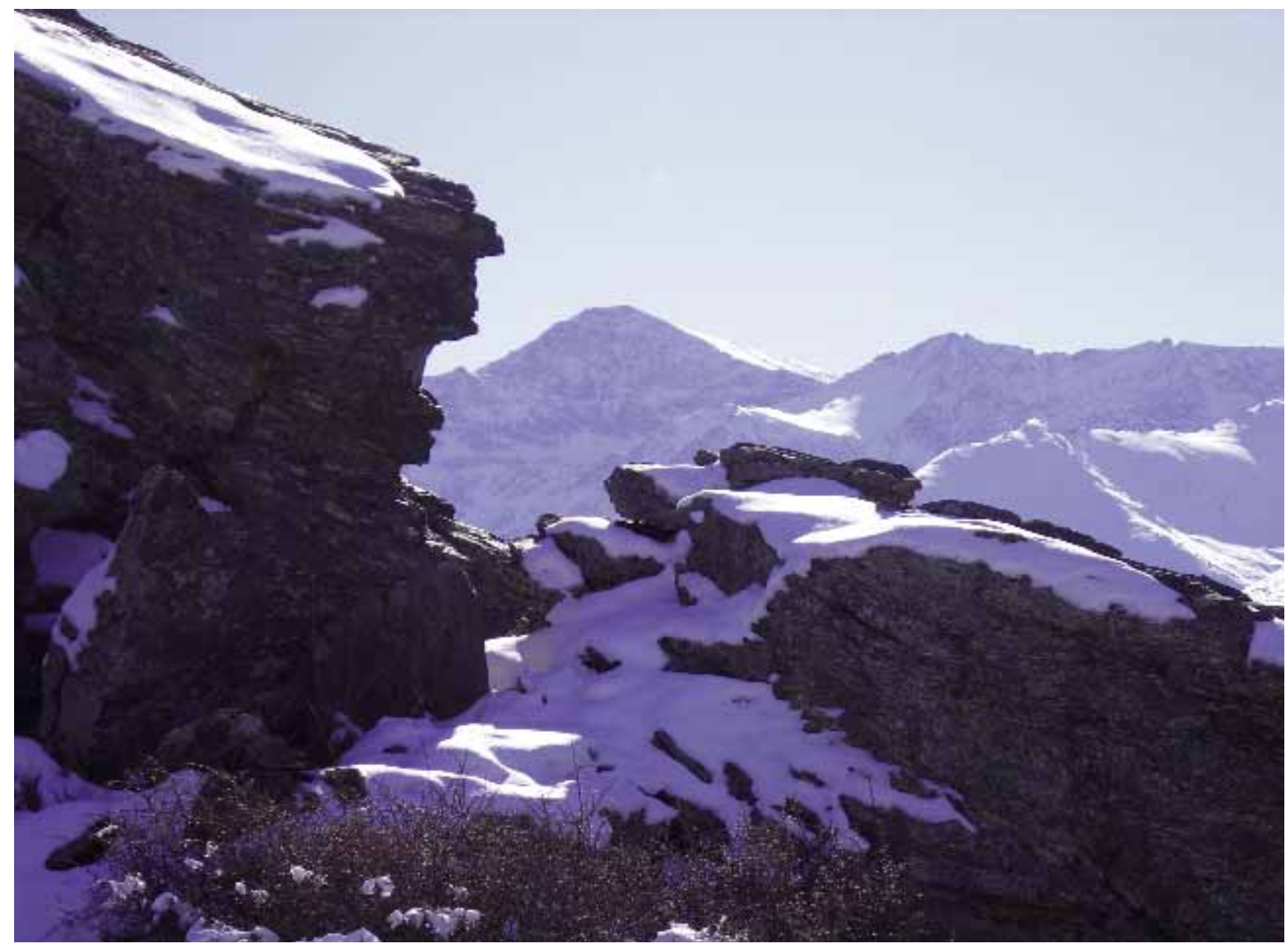




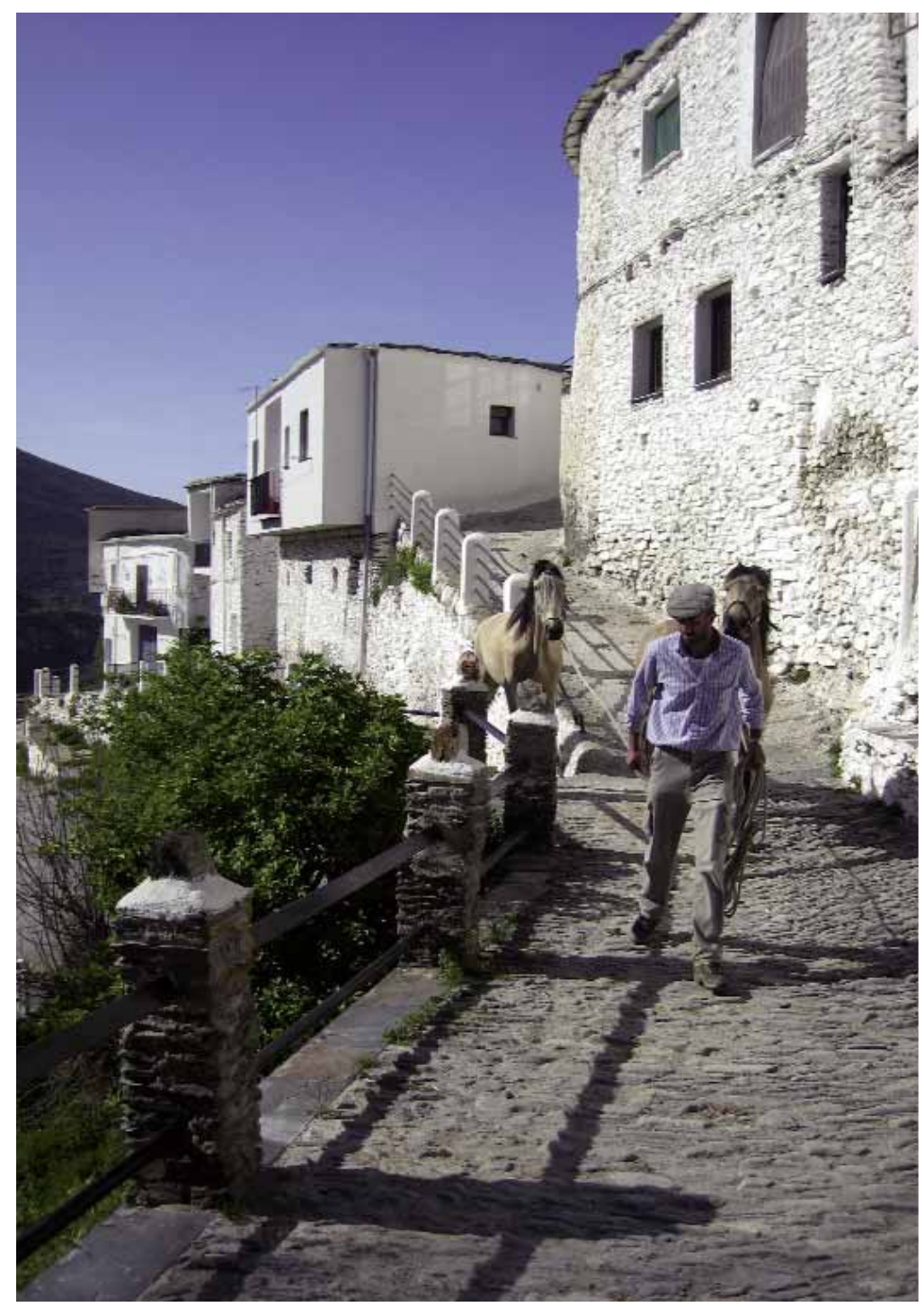

(1) Caballos. Trevélez (Granada) / Foto: MAtT Henderson

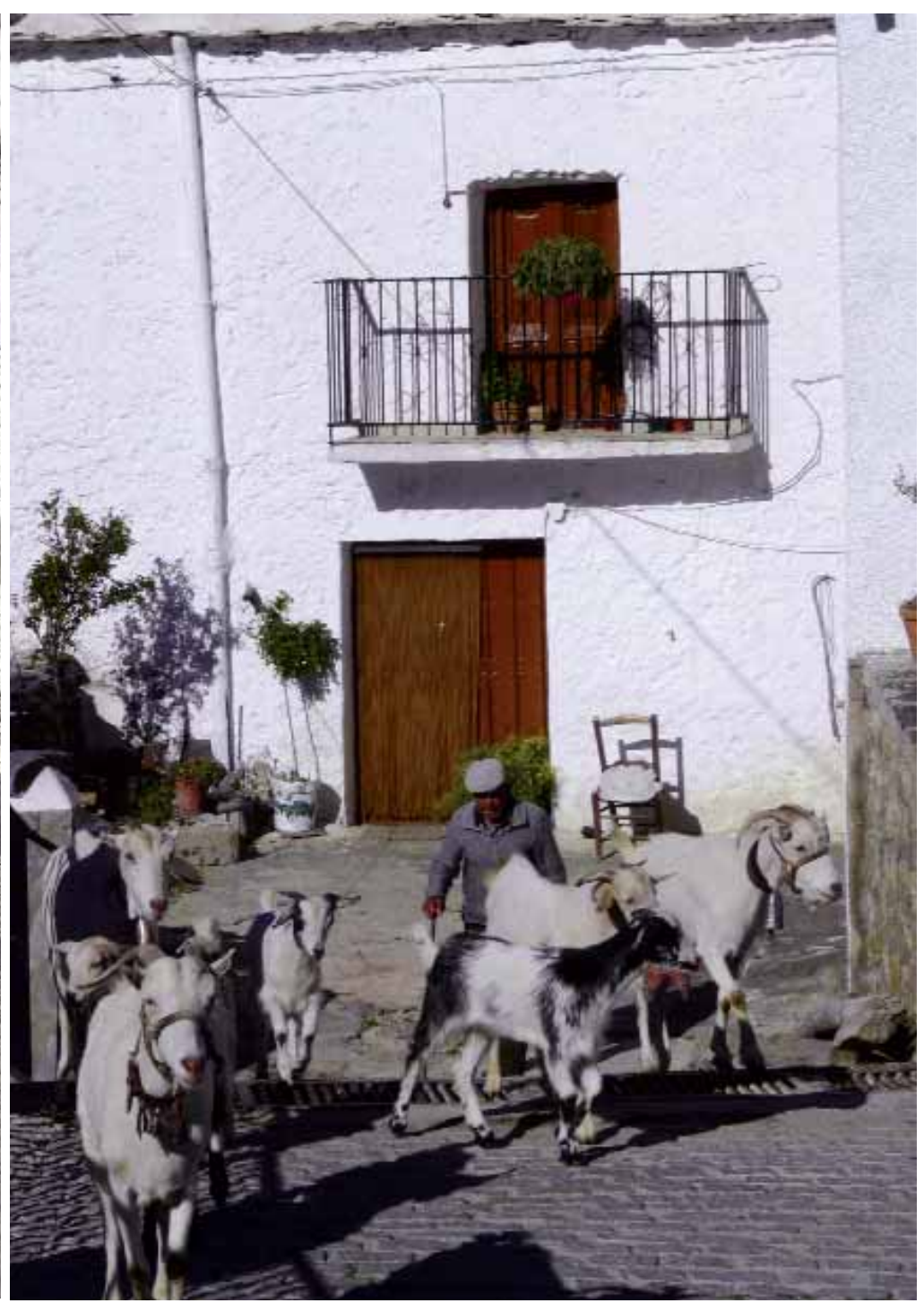

(1) Pastor de Trevélez / Foto: AndRÉs BREIJO 
no pueda sentir nunca jamás la perversa planta de los hombres". Y fue así como una tétrica comitiva ascendió desde lo hondo de la Alpujarra por las pizarras bruñidas hasta lo más encumbrado de la sierra, donde la tierra se corta de improviso en un tajo espantoso que sólo las águilas osan flanquear. Allí, a cubierto de las rapaces, resguardado por lajas diestramente dispuestas, en una de las más atrevidas cornisas, quedó tendido el cuerpo sin vida del rey ciego de Granada, sobre la faz imponente del león de la montaña, sobre la cumbre dominadora de su vieja Al-Andalus, que desde entonces lleva su imperecedero nombre: Muley Hacen, antiguamente, Mulhacén hoy.

Los manzanilleros de Güéjar y los pastores de Trevélez y Capileira fueron los únicos que durante siglos pusieron sus pies sobre la cumbre del rey de Sierra Nevada, hasta que un célebre botánico valenciano, Simón de Rojas Clemente, subió hasta su cima en el ya lejano año de 1804 para medir su altura y recolectar plantas para una Historia natural del reino de Granada que nunca pudo concluir. Sí realizó una dificilísima medición con procedimientos rudimentarios desde el Mulhacén hasta la misma playa de Castell de Ferro, de la que resultó para el Cerro una altura de 3556 metros, 85 más que la que realizó para el Veleta un año más tarde; ambas mediciones son razonablemente correctas para la época y de las mismas lo que quedó perfectamente claro fue la supremacía del uno sobre el otro, innegable desde entonces. "Muchos cavilosos -diría Clemente- se empeñaban en que Veleta es lo más alto de Sierra Nevada, fundados en el informe de sus malditos ojos y en la hora mal observada en que deja de bañar el sol cada cumbre...Tengo pues la satisfacción de haber hecho en medida de alturas la operación más exacta y la única en su especie".

Llevaba razón Simón de Rojas Clemente en lo de la altura y cuando en 1879 se realizó el enlace geodésico entre Europa y Africa a través del Mulhacén y la Tetica de Bacares, se pudo comprobar la supremacía del Mulhacén sobre todos los demás con sus poco más de 3 481 metros sobre el nivel del mar; algo menos de lo que decía Clemente, pero también algo más que el Veleta.

De aquella hazaña científica quedó el primer camino carretero al Mulhacén, por donde desde la Alpujarra tuvieron que transportar en carros tirados por bueyes la pesada maquinaria y donde erigieron unas construcciones que durante varios meses albergaron a los militares de la Comisión Geodésica. Fue un acontecimiento de importancia internacional que contribuyó a mejorar el conocimiento que entonces se tenía sobre las dimensiones y la forma de la tierra, al conseguir medir el arco de meridiano más grande logrado hasta entonces; el acierto mereció a su protagonista, el general Carlos Ibáñez de Ibero, el título de marqués de Mulhacén.

Sobre las ruinas de aquellas construcciones los habitantes de Trevélez levantaron una ermita en 1913 e instalaron en ella una imagen de la Virgen de las Nieves; la ermita estuvo en pie hasta 1922, fue reconstruida en 1931 y pronto volvió a ser víctima de las inclemencias del tiempo; pero aquello fue el origen de una tradición romera que cada 5 de agosto lleva a la cima del Mulhacén cada vez a más gente de uno y otro lado de la Sierra desde hace casi cien años.

Y sobre las ruinas de aquel camino carretero de los geodestas se construyó una pista para vehículos a motor, que desde entonces ha sido el origen de todos los males del Mulhacén. Se pensaba instalar allí un repetidor de televisión; afortunadamente se llevó a Lújar, pero ello no fue obstáculo para que el 17 de mayo de 1964 los periódicos recogieran la gran hazaña de que por primera vez un vehículo autopropulsado, un horrible Muskeg, pisaba la cima del Mulhacén. Y en 1974 se acondicionó aún más, para facilitar una subida hasta la misma cumbre, a todas luces innecesaria.

Así, hasta que en 1994 el Ministerio de Defensa intentó construir un radar en el Mulhacén,

\section{En la web}

Asociación de Desarrollo Rural de La Alpujarra

www.adr-alpujarra.com/html/indexPublica.php

Asociación Sierra Nevada Sostenible www.sierranevadasostenible.com

Web de la comarca de la Alpujarra www.la-alpujarra.org

Páginas que entre otros servicios ofrecen información cultural de interés de la comarca, por ejemplo sobre fiestas $\mathrm{y}$ tradiciones $\mathrm{o}$ agentes de desarrollo de la zona.

Biblioteca Pública Hurtado de Mendoza, de Órgiva

www.bibliotecaspublicas.es/orgiva/informacion.htm Cuenta con información de los servicios y actividades de la Biblioteca Municipal. Permite la búsqueda en el catálogo en línea, integrado en el Catálogo de las Bibliotecas Públicas de Andalucía.

Ficha del Observatorio Virtual del Paisaje Mediterráneo

www.paysmed.net/docs/osservatorio/andalucia/ Pdf_Andalucia/AN-29\%20Alpujarra\%20alta\%

20Sierra\%20Nevada.pdf

Ficha de La Alpujarra Alta y Sierra Nevada del Portal del Paisaje Mediterráneo.

FEI Trovo Alpujarreño (Blog) trovoalpujarra.blogspot.com

Este blog es un archivo digital que recopila y permite el acceso a información de diversa indole sobre el Trovo Alpujarreño. 


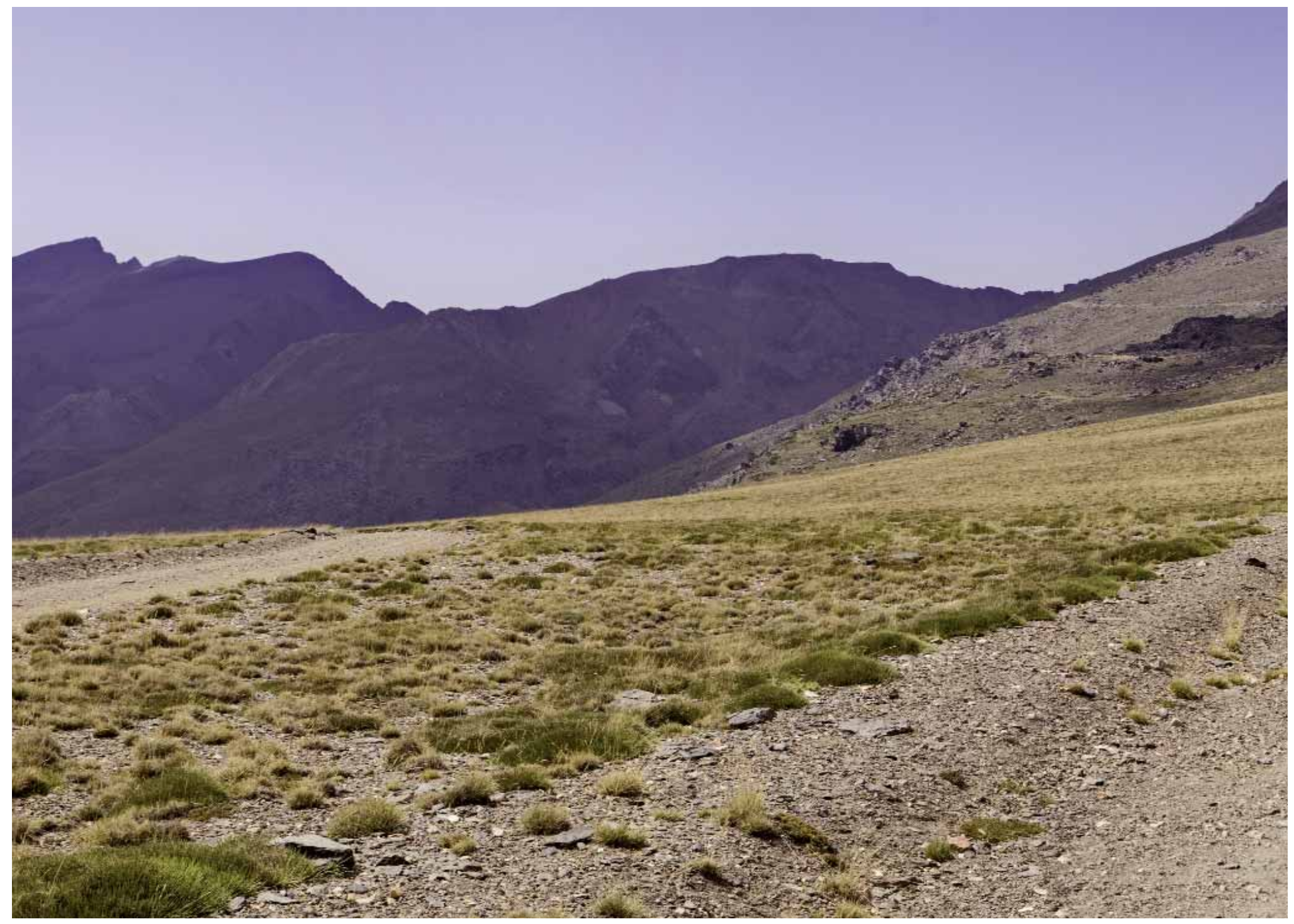

(1) El Chorrillo, donde comienza el camino carretero hacia el Mulhacén / Foto: JUAN CARLoS CAZALLA, IAPH

La movilización de los

montañeros granadinos

consiguió paralizar la

construcción de un radar

en el Mulhacén que hubiera destrozado para siempre la cima y que la movilización de los montañeros granadinos consiguió parar a tiempo.

Hoy, el Mulhacén soporta sobre su corona los restos de aquellas construcciones y de la ermita de los alpujarreños, pero las águilas ya pueden volar sobre su cima sin temor a ser espantadas ni por un Muskeg ni por un todoterreno. El Mulhacén, salvaje y libre, es una consigna cada día más veraz, parecido al que encontraron aquellos primeros viajeros del XIX que escribieron bellísimas descripciones de su experiencia serrana.

El suizo Edmond Boissier lo visitó en 1837 y dejó su testimonio en un soberbio libro, Viaje botánico al Sur de España durante el año 1837; el francés Teófilo Gautier cuenta que estuvo cerca del Mulhacén, seguramente fue en el Veleta, en 1840; el alemán Moritz Willkomm lo hizo en 1844 y lo narró en otro libro, 


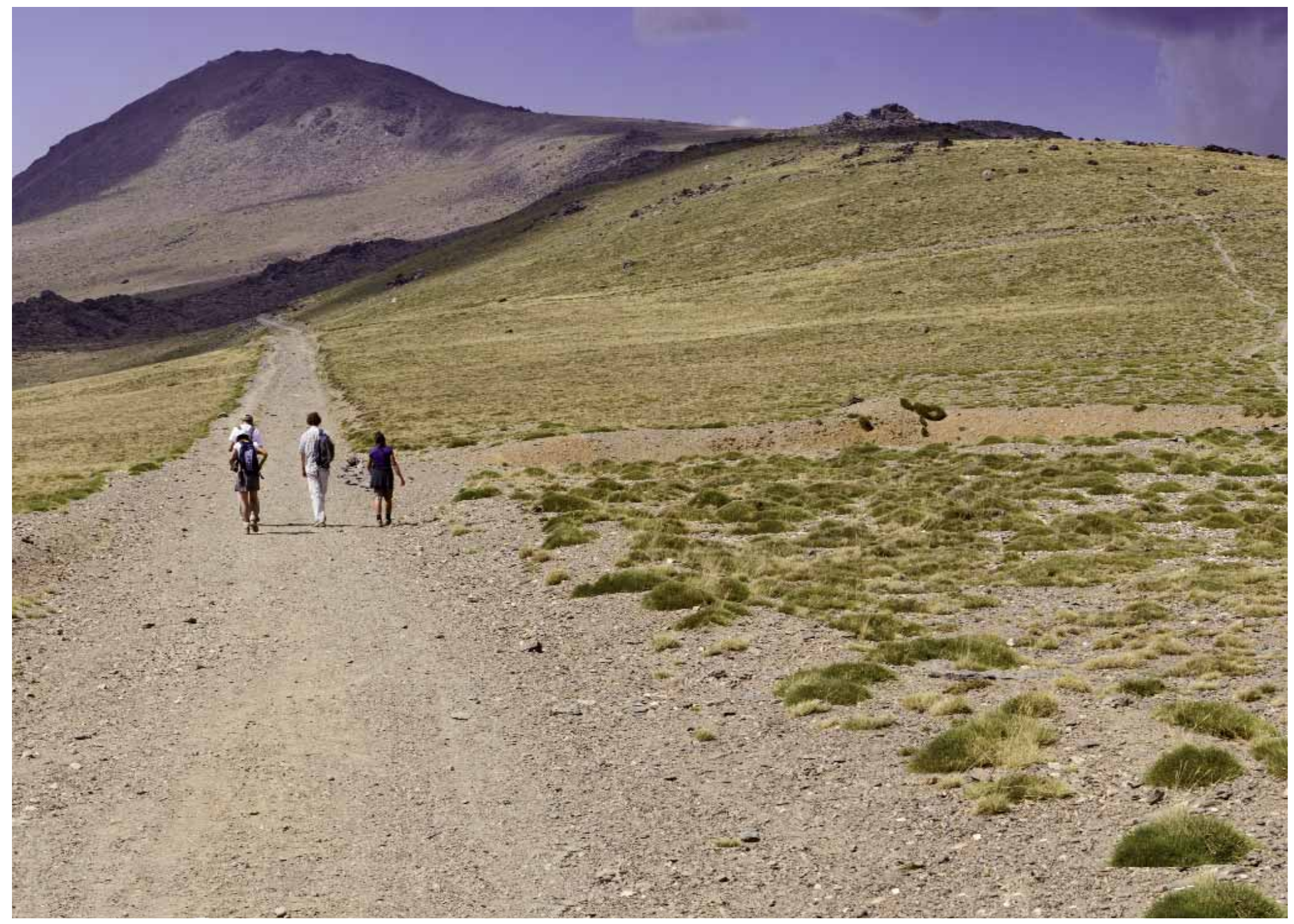

Las Sierras de Granada. Después lo hicieron los también alemanes Máximo Hertting y Johannes Rein, el malagueño-granadino Luis de Rute, el granadino-almeriense Antonio Rubio y a partir de ahí son ya frecuentes los testimonios granadinos de los socios del Centro Artístico y de la más antigua de las sociedades montañeras: los legendarios "Diez Amigos Limited".

Desde una perspectiva más literaria que investigadora o montañera, también Sierra Nevada y el Mulhacén encontraron su hueco en el trabajo de los accitanos Torcuato Tárrago en el género de la novela ( $A$ doce mil pies de altura, 1872) y Pedro Antonio de Alarcón en el libro de viajes La Alpujarra (1874), así como en los poetas José Zorrilla, Baltasar Lirola, Vicente Moreno, Miguel Gutiérrez, Narciso Díaz de Escobar y el propio Ángel Ganivet, influidos todos ellos por el orientalismo del primero que, como escribió Gallego Morell, ven en el Mulhacén el perfil de un moro con turbante de nieve: "el siglo XIX es el del Mulhacén, a él suben los primeros excursionistas, se enlaza con el talante morisco de las Alpujarras, con las lágrimas de Boabdil, con el Aben-Humeya de la historia o de Villaespesa, con los jamones de Trevélez, con los escritores costumbristas que tanto brillaron en el siglo XIX granadino".

Ahí estuvo y ahí está el Mulhacén, para que desde Trevélez o Capileira, por la Carigüela o desde la mucho más difícil subida por el Valdecasillas, el nacimiento más alto del Genil, pueda ser ascendido y disfrutado, nunca dominado ni vencido, porque como en casi todo, la naturaleza tendrá siempre la última palabra. 